\title{
Effects of p27Kip1 on cell cycle status and viability in A549 lung adenocarcinoma cells
}

\author{
T. Ishii*, M. Fujishiro*, M. Masuda*, Y. Goshima", H. Kitamura ${ }^{+}$, S. Teramoto§, T. Matsuse*
}

Effects of p27Kip1 on cell cycle status and viability in A549 lung adenocarcinoma cells. T. Ishii, M. Fujishiro, M. Masuda, Y. Goshima, H. Kitamura, S. Teramoto, T. Matsuse. C) ERS Journals Ltd 2004.

ABSTRACT: p27Kip1 is a cyclin-dependent kinase inhibitor, it negatively regulates G1 progression and is reported to modulate apoptosis. Phosphorylation of this protein is thought to regulate its intracellular localisation and affect its stability.

The aim of this study was to regulate p27Kip1 expression levels, and to examine how this protein affects cell cycle status and modulates viability in A549 lung adenocarcinoma cells. In addition, the association between phosphorylation status of p27Kip1 and its intracellular localisation was investigated, using expression vectors with cDNA of p27Kip1 or mutants in which the phosphorylation sites had been mutated.

Although overexpression of p27Kip1 reduced cell cycle progression, its removal did not change cell cycle status. Modest induction of p27Kip1 rescued adenovector-induced apoptosis and its removal with short interfering RNA increased spontaneous cell death. It was also observed that p27Kip1 localised mainly in the cytoplasm, and forced expression of p27Kip1 cDNA with the substitution of serine (S) 10, threonine (T) 157 and T198 to glutamate (phosphor-mimetic) induced its cytoplasmic localisation.

In conclusion, p27Kip1, when expressed physiologically, exists mainly in the cytoplasm, has little effect on cell cycle status and contributes viability in A549 lung adenocarcinoma cells. It was also surmised that intracellular localisation of p27Kip1 dominates its function and that its localisation was partly determined by its phosphorylation.

Eur Respir J 2004; 23: 665-670.

\begin{abstract}
*Dept of Pulmonary Medicine, Yokohama City University Medical Center, Yokohama, \#Dept of Microbiology, Dokkyo University, School of Medicine, Dept of Molecular Pharmacology and Neurobiology, Yokohama City University Graduate School of Medicine, Yokohama, ${ }^{+}$Dept of Pathology, Yokohama City University School of Medicine, Yokohama, and ${ }^{\mathrm{S}}$ Dept of Geriatric Medicine, University of Tokyo, Tokyo, Japan.
\end{abstract}

Correspondence: T. Matsuse, Dept of Pulmonary Medicine, Yokohama City University Medical Center, 4-57 Urahune-cho Minami-ku, Yokohama City 232-0024, Japan.

Fax: 81452412812

E-mail: matsuse-tky@umin.ac.jp

Keywords: Apoptosis, cell cycle, intracellular localisation, p27Kip1, phosphorylation

Received: August 222003

Accepted after revision: January 202004

T. Ishii is a Research Fellow of the Japan Society for the Promotion of Science. This study was supported by a grant from Grant-inAid for Scientific Research (B) (2) (\#1355 7054) and partly supported by a grant from Research Fellowships of the Japan Society for the Promotion of Science for Young Scientists.
p27Kip1 is one of the cyclin-dependent kinase (CDK) inhibitors (CDKIs), which suppress the activity of CDKs and regulate the mammalian cell cycle [1]. p27Kip1 negatively regulates transition from the $\mathrm{G} 1$ to the $\mathrm{S}$ phase of the cell cycle, by binding to $\mathrm{G} 1$ cyclin-CDK complexes [1], resulting in inhibition of proliferation. A loss or decrease in the level of $\mathrm{p} 27 \mathrm{Kip} 1$ concentration is frequently observed in many human cancers [2], including lung cancer, and reduced levels of p27Kip1 are reported to be an independent prognostic factor correlating with the overall survival times in nonsmall cell lung carcinoma (NSCLC) [3]. Although forced expression of p27Kip1 induces cell cycle arrest in lung adenocarcinoma cells [4], it is not well known how p27Kip1 actually modulates the cell cycle under physiological conditions in NSCLC.

In addition, p27Kipl is reported to have an effect on apoptosis. At first, it was reported that overexpression of p27Kip1 induced apoptosis in various cell lines [5,6] and in lung cancer cells [4]. However, it was also shown that p27Kip1 has a role in the protection of apoptosis induced by deprivation of growth factor [7], in small cell carcinoma of the lung in unfavourable microenvironments [8] and against

For editorial comments see page 663. chemotherapeutic agents $[9,10]$. Thus, it is now controversial whether p27Kip1 induces or reduces apoptosis.

The activity of $\mathrm{p} 27 \mathrm{Kip} 1$ is regulated by its concentration and subcellular localisation [2]. The concentration of p27Kip1 is thought to be controlled mainly by the ubiquitin-proteasome pathway, and this ubiquitination is known to be promoted by its phosphorylation on threonine 187 by the cyclinE-CDK2 complex $[11,12]$. Serine 10, threonine 157 and threonine 198 are also thought to be the targets of phosphorylation, and their phosphorylation is considered to regulate the intracellular localisation and the protein stability of p27Kip1 [13-16]. However, the mechanisms that regulate intracellular localisation of p27Kip1 have not been extensively examined in NSCLC cells.

The aim of this study was to investigate how the expression level of p27Kip1 affects the status of cell cycle and apoptosis, and how phosphorylation of p27Kip1 affects its subcellular localisation in A549 human lung adenocarcinoma cells.

\section{Material and methods}

\section{Cell culture}

Human lung adenocarcinoma-derived A549 cells, PC-14 cells and RERF-LC-KJ cells, and human embryo lung 
fibroblast-derived HFL-1 cells were obtained from Riken Cell Bank (Tsukuba-city, Japan) and maintained in Dulbecco's modified Eagle's medium (DMEM; Gibco, Life Technologies, Inc., New York, NY, USA) containing 10\% foetal bovine serum (FBS; Interon Inc., New York, NY, USA), $100 \mathrm{U} \cdot \mathrm{mL}^{-1}$ penicillin and $100 \mu \mathrm{g} \cdot \mathrm{mL}^{-1}$ streptomycin.

\section{Recombinant adenoviral vectors}

The recombinant adenovirus containing p27 cDNA (Adp27) was constructed using the Adeno-X Expression System (Clontech Laboratories, Inc., Palo Alto, CA, USA), as follows. The cDNA of p27 (kindly provided by H. Kitamura, Dept of Pathology, Yokohama City University School of Medicine, Yokohama, Japan) was subcloned into the NotI and ApaI sites of the multiple cloning site of the adenoviral shuttle vector, pShuttle. This shuttle vector was digested with I-CeuI and PI-SceI and was ligated to Adeno-X DNA. The Adeno-X plasmid DNA was then digested with PacI and was transfected into HEK293 cells using the FuGENE 6 Transfection Reagent (Roche Diagnostics GmbH, Mannheim, Germany), according to the manufacturer's protocol. The HEK 293 cells were maintained in DMEM containing $10 \%$ FBS, $100 \mathrm{U} \cdot \mathrm{mL}^{-1}$ penicillin and $100 \mu \mathrm{g} \cdot \mathrm{mL}^{-1}$ streptomycin, until the onset of cytopathic effect. The function of generated adenovirus was confirmed by immunoblot of p27 and the titre was determined using the Adeno-X rapid titre kit (Clontech Laboratories), according to the manufacturer's protocol.

Cells were seeded at a density of $1 \times 10^{5}$ cells $\cdot$ well $^{-1}$ in DMEM with $10 \%$ FBS in a six-well culture plate and, $24 \mathrm{~h}$ later, they were infected with adenovector at indicated concentrations for $1 \mathrm{~h}$. Subsequently, they were incubated with DMEM with 10\% FBS for further experiments. Adenovector-expressing $\beta$-galactosidase (Ad-lacZ) was used as a control viral vector.

\section{Construction of siRNA and transfection}

Cells were seeded in a six-well culture plate and, $24 \mathrm{~h}$ later, double stranded (ds)RNAs transfection was carried out using oligofectamine (Invitrogen Corp., Carlsbad, CA, USA), according to the manufacturer's protocol. Forty-eight hours after transfection, further experiments were performed. dsRNAs corresponded to nucleotides $470-488$ of the p27Kip1-coding region (CCGACGATTCTTCTACTCA), purchased from JBioS (Saitama, Japan). Control (nonsilencing) short interfering (si)RNA (Qiagen-Xeragon. Germantown, MD, USA) was used as a nonrelated control dsRNA.

\section{Construction of plasmids and site-directed mutagenesis, and transfection}

The cDNA was inserted between the EcoRI and SacII sites of a plasmid vector pIRES2-EGFP (Clontech Laboratories), which carries the enhanced green fluorescent protein (EGFP) gene expressed in an internal ribosomal entry site (IRES)dependent manner. The p27Kip1 mutants were generated by replacing serine 10 , threonine 157 , threonine 187 and threonine 198 with alanine or glutamate, using the QuickChange site-directed mutagenesis kit (Stratagen, La Jolla, CA, USA), according to the manufacturer's protocol. Takara Bio Inc. (Otsu-city, Japan) confirmed the mutated sequences of p27Kip1 cDNA.

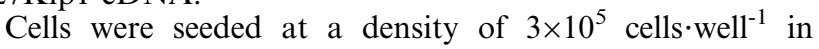
DMEM with $10 \%$ FBS in a six-well culture plate and, $24 \mathrm{~h}$ later, DNA transfection was carried out using the GeneJammer Transfection Reagent (Stratagene) according to the manufacturer's protocol. Forty-eight hours after transfection, cells were analysed for immunoblot.

\section{Flow cytometry}

Apoptosis and necrosis of the cells were analysed as described previously [17], with a slight modification. Surface exposure of phosphatidylserine (PS), thought to be the early signal of apoptosis, was monitored using the high-affinitybinding properties of annexin V for PS. Membrane disruption indicating necrosis was assessed using propidium iodide (PI) uptake. Cells were washed twice with phosphate-buffered saline (PBS), and incubated with $5 \mu \mathrm{L}$ annexin V-Fluos and $5 \mu \mathrm{L}$ PI solution (Roche Diagnostics $\mathrm{GmbH}$ ) in $1 \times$ binding buffer $(10 \mathrm{mM}$ Hepes, pH 7.4, $140 \mathrm{mM} \mathrm{NaCl}, 2.5 \mathrm{mM}$ $\mathrm{CaCl}_{2}$ ), at a final concentration of $1 \times 10^{6}$ cells $100 \mu \mathrm{L}^{-1}$ solution for $15 \mathrm{~min}$. Subsequently, the cells were analysed by flow cytometry for fluorescence from Fluos-conjugated annexin $\mathrm{V}$ (emission wavelength $518 \mathrm{~nm}$ ) and PI (emission wavelength $617 \mathrm{~nm}$ ), which was analysed with fluorescence channel (FL) 1 and FL2, respectively. Dual labelling of cells with a combination of annexin V and PI allowed the detection and differentiation of annexin-negative (-) and PI-negative (-) viable cells, annexin-positive $(+)$ and PI-negative (-) apoptotic cells, and PI-positive $(+)$ necrotic cells. The cell percentages for apoptosis and necrosis were calculated concretely as follows:

$$
\begin{aligned}
& \operatorname{apoptosis}(\%) \cong \frac{\operatorname{annexinV}(+) \text { cells and } \mathrm{PI}(-) \text { cells } \times 100(\%)}{\mathrm{PI}(-) \text { cells }} \\
& \text { necrosis }(\%) \cong \frac{\mathrm{PI}(+) \text { cells } \times 100(\%)}{\text { all cells }}
\end{aligned}
$$

For cell cycle analysis, cells were collected by trypsinisation, washed twice with PBS, fixed with $70 \%$ ethanol and stored at $4^{\circ} \mathrm{C}$ for $24 \mathrm{~h}$. These cells were treated with RNase A (Roche Diagnostics $\mathrm{GmbH}$ ) and were stained with PI (Molecular Probes, Inc. Eugene, OR, USA) at a final concentration of $25 \mu \mathrm{g} \cdot \mathrm{mL}^{-1}$. The PI fluorescence of nuclei was measured using FACScan with FL2.

All FACS data were analysed with CellQuest software (Becton Dickinson, CA, USA) and the ModFit LT software (Becton Dickinson).

\section{Immunoblots}

After gentle washing with PBS, the cell layer was lysed with a mixture of RIPA buffer $(50 \mathrm{mM}$ Tris/ $\mathrm{HCl}, \mathrm{pH} 7.5,150 \mathrm{mM}$ $\mathrm{NaCl}, 1 \%$ Nonidet P-40, $0.5 \%$ sodium deoxycholate, $0.1 \%$ SDS) and the stock solution of Complete Mini protease inhibitor cocktail (Roche Diagnostics $\mathrm{GmbH}$ ), according to the manufacturer's protocol. Lysates were centrifuged $(20,000 \times g$, $30 \mathrm{~min}, 4^{\circ} \mathrm{C}$ ) and supernatants were stored at $-80^{\circ} \mathrm{C}$. These lysates $(100 \mu \mathrm{g})$ were mixed with $2 \times$ sample buffer $(0.1 \mathrm{M}$ Tris$\mathrm{HCl}, \mathrm{pH} 6.8,4 \%$ SDS, $6 \% \beta$-mercaptoethanol, $20 \%$ glycerol, $0.004 \%$ bromophenol blue), boiled at $100^{\circ} \mathrm{C}$ for $10 \mathrm{~min}$, and immediately subjected to SDS-PAGE with ECL protein molecular weight markers (Amersham Biosciences Corp, Piscataway, NJ, USA). Precast $10 \%$ gels were used and electrophoresis was performed at a constant 200 V. After SDSPAGE, proteins were transferred to polyvinyliden difluoride (PVDF) membranes, and incubated with appropriate antibodies against human p27 (C-19; Santa Cruz Biotechnology, California, CA, USA), lamin B (Ab-1; Oncogene, San Diego, CA, USA) and mouse anti- $\alpha$ tubulin (Zymed Laboratories, 
San Francisco, CA, USA). The ECL Western blotting analysis system (Amersham Biosciences Corp.) was used for immunoblots detected with FAS-1000 Lumino Imaging Analyser (Toyobo Biochemicals, Tokyo, Japan). Gels, membranes and instruments for SDS-PAGE and immunoblotting were purchased from ATTO Corporation (Tokyo, Japan). Recombinant protein of p27Kip1 (Santa Cruz Biotechnology) was used as a positive control.

\section{Subcellular fractionation}

For subcellular fractionation, NE-PER nuclear and cytoplasmic extraction reagents (Pierce, Rockford, IL, USA) were used, according to the manufacturer's protocol. The localisation of the protein was confirmed by immunoblots with antilamin B (as nuclear portion) and anti-tubulin (as cytoplasmic portion) antibodies, respectively.

\section{Statistical methods}

Data are presented as mean \pm SD. Comparisons were made using unpaired t-tests or ANOVA when appropriate. A pvalue $<0.05$ was considered to indicate statistical significance.

\section{Results}

p27Kipl negatively regulates cell cycle progression in a modest manner

First, A549 cells were examined to determine is they were an appropriate representative of NSCLC cell lines in term of p27Kip1 expression. The expression level of p27Kipl was examined in three NSCLC cell lines, namely A549, PC-14 and RERF-LC-KJ, with immunoblot. As shown in figure 1a, all these cell lines expressed p27Kip1 in a proliferative state and A549 cells expressed a moderate level of p27Kip1, as compared to the other NSCLC cell lines. Thus, A549 cells were mainly used in the following experiments.

p27Kip1 expression level was regulated upward with adenovector and downward with the siRNA method in

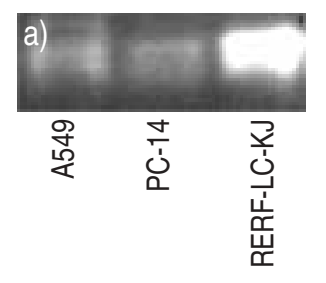

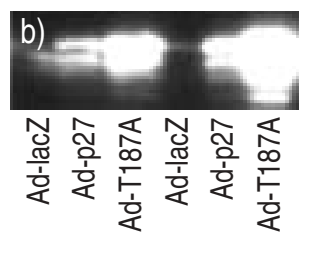

Day 2 Day 5

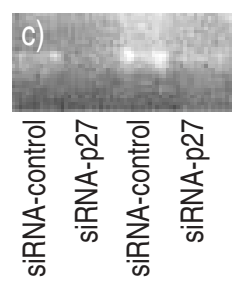

Day 2 Day 5
Fig. 1.-a) The expression level of p27Kip1 in three nonsmall cell lung cancer (NSCLC) cell lines, A549, PC-14 and RERF-LC-KJ, with immunoblot. All these cell lines expressed p27Kip1 in a proliferative state. A549 cells expressed a moderate level of p27Kip1 as compared to other NSCLC cell lines. b) Detection of p27Kip1 protein expression after infection with adenovirus by immunoblotting. p27Kip1 was overexpressed in the cells infected with Ad-p27 and Ad-T187A, as compared to those infected with Ad-lacZ. The amount of p27Kipl in Ad-T187A-transduced cells was higher than that in Ad-p27-transduced cells. These effects lasted at least 5 days after infection. c) Detection of p27Kip1 protein expression in A549 cells after transfection of siRNA by immunoblotting. Expression of p27Kip1 was more on day 5 than day 2 after transfection of siRNAcontrol, because of the confluent state of the cells, and its expression was reduced both on day 2 and day 5 after transfection of siRNAp27Kip1.
A549 cells. As shown in the immunoblot (fig. 1b), p27Kip1 was overexpressed in the cells infected with Ad-p27 and AdT187A, as compared to those infected with Ad-lacZ, and the amount of p27Kip1 in Ad-T187A-transduced cells was higher than that in Ad-p27-transduced cells. Inversely, siRNA of p27Kip1 downregulated the endogenous p27Kip1 as detected in mock cells. This was also confirmed with immunoblotting (fig. 1c).

The effects of $\mathrm{p} 27 \mathrm{Kip} 1$ on cell cycle were examined. Forced expression of p27Kip1 with Ad-p27 or Ad-T187A repressed cell cycle progression and increased the $\mathrm{G} 0 / \mathrm{G} 1$ proportion of the cells. Ad-T187A had a stronger effect than Ad-p27, which is consistent with the results of previous studies [4, 11]. However, transfection of $\mathrm{p} 27 \mathrm{Kip} 1$ siRNA downregulation of p27Kip1, did not affect cell cycle status at days 2 and 5 after transfection. This finding was unexpected (fig. 2).

\section{p27Kipl rescued cells from apoptosis}

A549 cells were made to overexpress p27Kip1 with adenoviral vectors to examine its capacity on the induction of apoptosis. It was confirmed by immunoblotting that the wildtype and mutant protein of p27Kip1 was overexpressed on days 2 and 5 after infection of Ad-p27 and Ad-T187A (fig. 1b). Ad-lacZ induced apoptosis and necrosis in A549 cells in a time- and dose-dependent manner (fig. 3a and b), speculatively due to the cytotoxic effect of the adenoviral vector [18]. Ad-p27 significantly reduced the proportion of apoptosis and necrosis both on days 2 and 5. Although Ad-T187A reduced cell death, this effect seemed less than that of Ad-p27, which might suggest that extremely high and long expression of $\mathrm{p} 27 \mathrm{Kip} 1$ could induce apoptosis, consistent with previous reports [19].

In addition, the effect of p27Kip1 removal on cell viability was also investigated. It was confirmed by immunoblotting that the expression of $\mathrm{p} 27 \mathrm{Kip} 1$ was reduced both on days 2 and 5 after transfection of siRNA-p27Kip1 (fig. 1c).

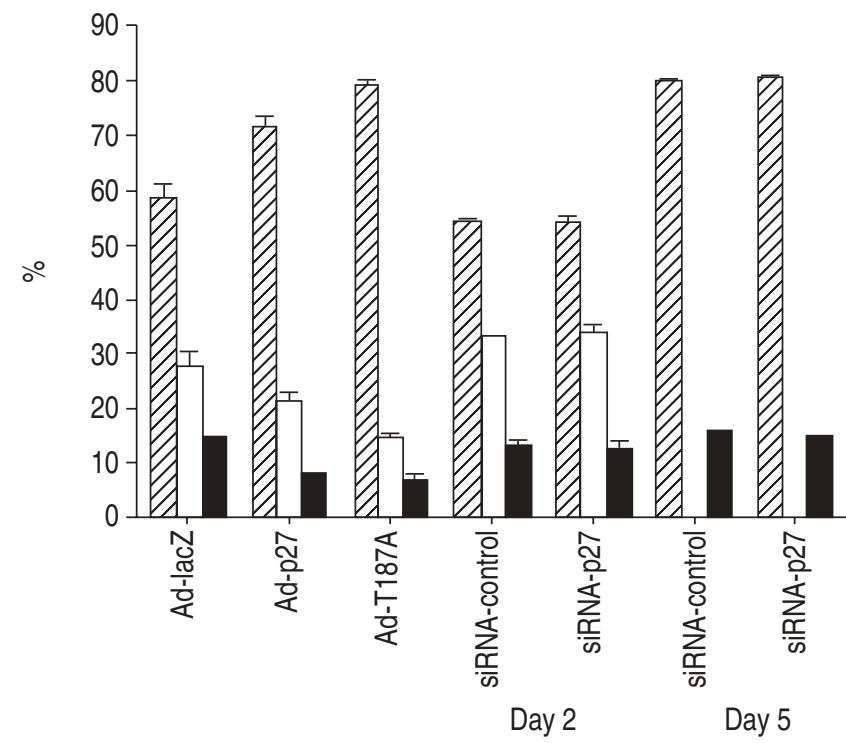

Fig. 2. - Forced expression of p27Kip1 repressed cell cycle progression and increased the $\mathrm{G} 0 / \mathrm{G} 1(\mathbb{Z})$ proportion of the cells. Unexpectedly, transfection of p27Kip1 siRNA downregulation of p27Kip1 did not affect cell cycle status on day 2 or day 5 after transfection (the G0/G1 proportion of the cells increased on day 5 because of the confluent state of the cells). Data are presented as means \pm SD $(n=3)$. $\square: S$; G2/M. *: $\mathrm{p}<0.05 ; * *: \mathrm{p}<0.01$, as compared to the cells infected with Ad-lacZ or the cells transfected with siRNA-control. 

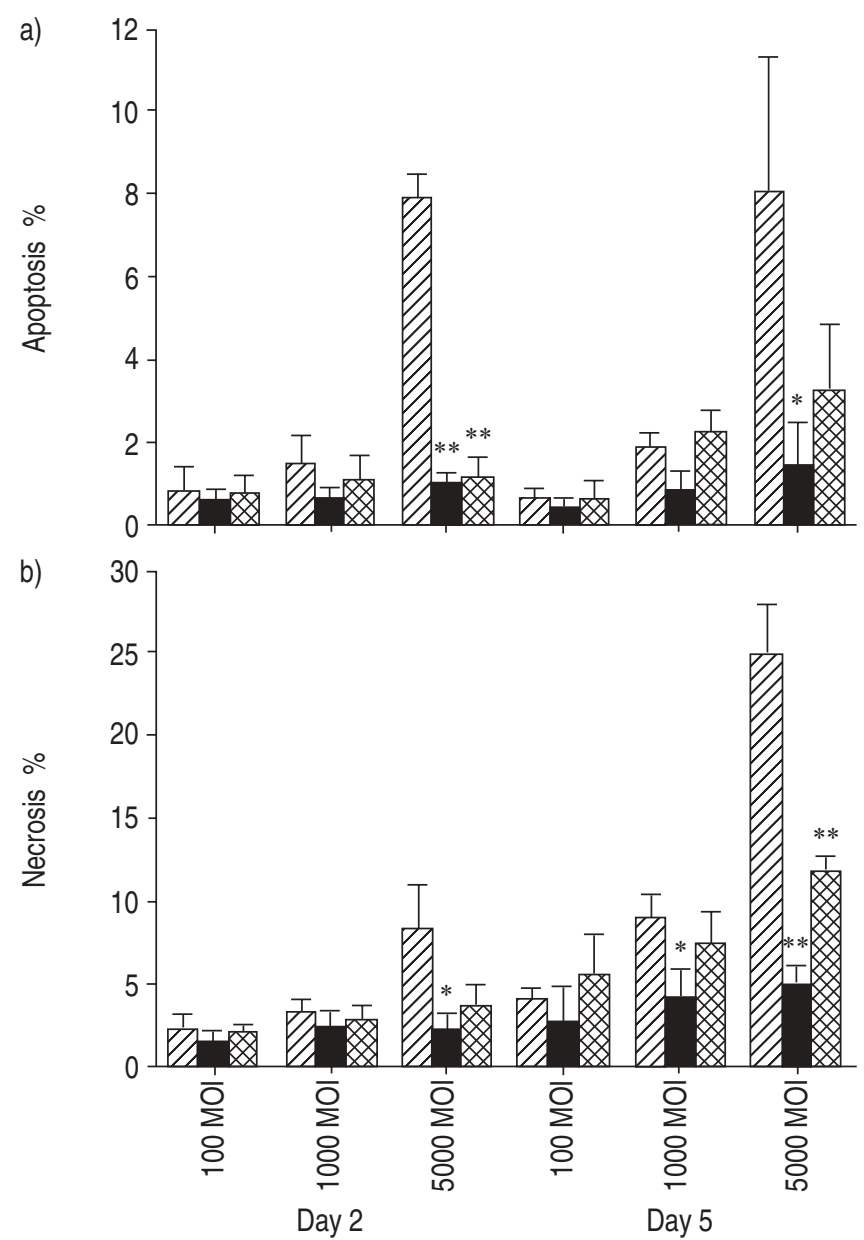

Fig. 3. - a) The proportion of apoptotic cells and b) the proportion of necrotic cells after forced expression of p27Kip1 in A549 cells. AdlacZ $(\mathbb{Z})$ induced apoptosis and necrosis in A549 cells in time- and dose-dependent manner, and Ad-p27 (ם) significantly reduced the proportion of apoptosis and necrosis both on day 2 and day 5. Data are presented as mean \pm SD $(n=3)$. $\quad$ : Ad-T187A. *: $\mathrm{p}<0.05$; **: $\mathrm{p}<0.01$, as compared to the cells infected with Ad-lacZ.

siRNA-p27Kip1 increased the proportion of apoptotic or necrotic cells in A549 cells (fig. 4a), human lung fibroblast HFL-1 (fig. 4b) and two other cell lines of human lung adenocarcinoma (PC-14 (fig. 4c) and RERF-LC-KJ). Thus, it was thought that $\mathrm{p} 27 \mathrm{Kip} 1$ contributed to the cell viability in the physiological expression.

Since reduction of p27Kip1 did not affect cell cycle status but induced cell death in A549 cells, it was speculated that p27Kipl exists little in the nucleus as a CDKI, but mainly in the cytoplasm, in order to prevent cell death. To check this possibility, the intracellular localisation of p27Kip1 was investigated in the proliferation state (fig. 5). It was observed that p27Kipl existed more in the cytoplasm than in the nucleus. These phenomena were also investigated in another lung-derived cell line, HFL-1. Although p27Kip1 was not present in the nucleus, it was still present in the cytoplasm of HFL-1 cells (fig. 5). Thus, it is conceivable that cytoplasmic p27Kipl might have a role in reducing cell death.

\section{Phosphorylation status of p27Kipl affects subcellular localisation}

From the observation described above, it was considered that $\mathrm{p} 27 \mathrm{Kip} 1$ mainly exists in the cytoplasm in the proliferation
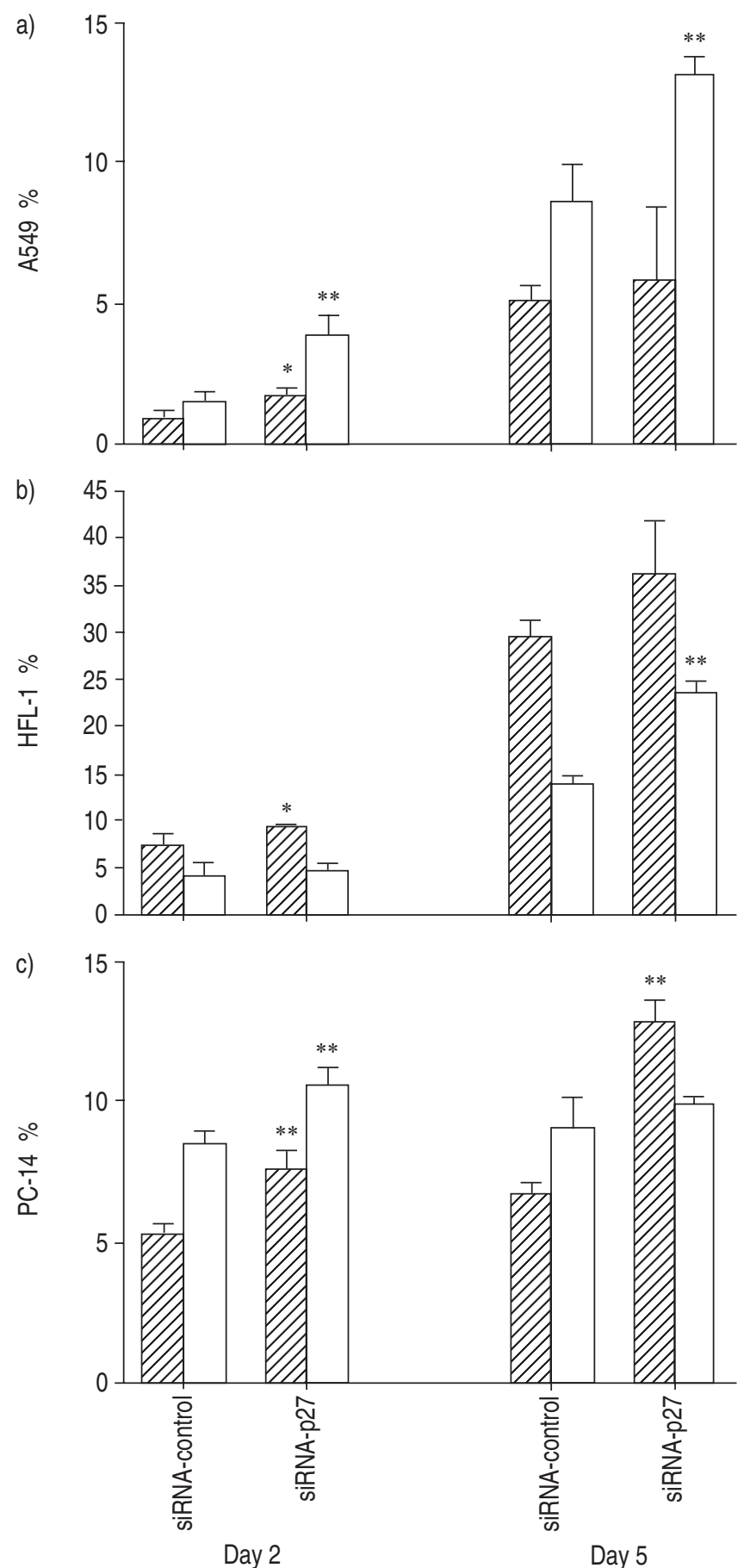

Fig. 4. - a) siRNA-p27Kip1 increased the proportion of apoptotic (Z्Z) or necrotic ( $\square$ ) cells in A549 cells, b) human lung fibroblast HFL-1 and c) two other cell lines of human lung adenocarcinoma, PC-14 and RERF-LC-KJ. Data are presented as mean \pm SD $(n=3) . *: p<0.05$; $* *: \mathrm{p}<0.01$, as compared to the cells transfected with short interfered RNA-control.

state, contributes to cell viability and scarcely affects cell cycle status in physiological expression. Simultaneously, forced expression of $\mathrm{p} 27 \mathrm{Kip} 1$ reduced cell cycle progression as a CDKI, which is thought to function in the nucleus [1]. Therefore, $\mathrm{p} 27 \mathrm{Kip} 1$ may have distinctive roles in the nucleus and the cytoplasm, respectively, and it is important to figure out the regulation of intracellular localisation of $\mathrm{p} 27 \mathrm{Kip} 1$.

Since serine 10, threonine 157 and threonine 198 are thought to regulate the intracellular localisation and protein 


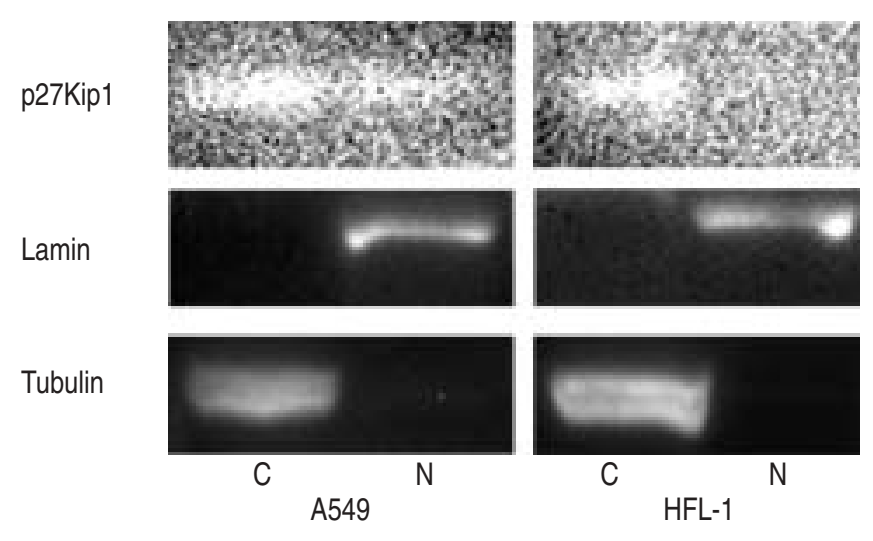

Fig. 5.-p27Kip1 mainly localised in cytoplasm (C) in the proliferation state. p27Kip1 was present more in the cytoplasm than in the nucleus (N) in A549 cells and HFL-1 cells.

stability of p27Kip1 [13-16], the association between the phosphorylation status of these residues and the intracellular localisation of p27Kip1 was investigated in A549 cells. Mutagenesis of p27Kip1 cDNA was performed, and, as a result, serine 10 (S10), threonine 157 (T157) and threonine 198 (T198) were substituted for glutamate (E) (phospho-mimetic) or alanine (A) (resistant to phosphorylation), respectively. These vectors were transfected into A549 cells to investigate the subcellular localisation of p27Kip1 with immunoblotting.

The consecutive immunoblots are shown in figure 6 (the phospho-mimetic mutants (E) and the mutants resistant to phosphorylation (A)). It was observed that all S10E, T157E and T198E protein localised in the cytoplasm, as compared to the overexpressed wildtype protein. By contrast, substitution of these amino acids with alanine did not seem to change the subcellular localisation of this protein. Taken together, it was shown that p27Kip1 preferably localised in the cytoplasm, and that its localisation could be regulated by the phosphorylation of S10, T157 and T198, this was also possible in A549 cells.

\section{Discussion}

p27Kip1 is one of the CDKIs and negatively regulates cell cycle progression by binding to $\mathrm{G} 1$ cyclin-CDK complexes [1]. A loss or decrease of $\mathrm{p} 27 \mathrm{Kip} 1$ concentration is frequently observed in many human cancers [2] and a reduced level of $\mathrm{p} 27 \mathrm{Kip} 1$ is reported to be an independent prognostic factor correlating with the overall survival times in NSCLC [3]. Although cytoplasmic displacement of p27Kip1 and its association with poor prognosis has also been reported in breast cancer [20], and this cytoplasmic localisation was also seen in several malignant tissues [2], this phenomena and its importance have not been examined in lung cancer. Thus, the aim of this study was to investigate the general characteristics of p27Kip1, the association between its role and its intracellular localisation, and the regulation of its localisation in A549 lung adenocarcinoma cells.

It was observed that forced expression of p27Kip1 repressed cell cycle progression and that the T187A mutant had a stronger effect than the p27 wildtype, which is consistent with the results of previous reports $[4,11]$. However, unexpectedly, downregulation of p27Kip1 using the siRNA method did not affect cell cycle status. This physiological expression of $\mathrm{p} 27 \mathrm{Kip} 1$ (this expression was confirmed by immunoblots (fig. 1)) could not be contributed to negative regulation of cell cycle progression in this amount.

Next, the association between p27Kipl and cell viability was investigated. Overexpression of $\mathrm{p} 27 \mathrm{Kip} 1$ was reported to induce apoptosis in various cell lines $[5,6]$ and in lung cancer cells [4]. However, this apoptosis-inducing effect could not be confirmed, and it was inversely observed that p27Kip1 has protective effects by reducing apoptosis or necrosis due to viral cytotoxicity and spontaneous cell death. It was recently reported that $\mathrm{p} 27 \mathrm{Kip} 1$ has a role in protection of apoptosis induced by deprivation of growth factor [7], in deprivation of isoleucine [8] and against chemotherapeutic agents [9, 10]. Therefore, $\mathrm{p} 27 \mathrm{Kip} 1$ has a protective role against cell death in several unfavourable conditions. It is possible that p27Kip1 could not induce apoptosis in this study because of the short period (5 days) of observation, which might not be sufficient to dephosphorylate the retinoblastoma gene product $(\mathrm{Rb})$, which is reported to be needed in this apoptotic process $[19,21]$.

The authors of this study speculate that p27Kip1, when expressed physiologically, scarcely affects cell cycle status but contributes to cell viability, and they also believe that this might be due to its intracellular localisation in this physiological status. In fact, it was observed that p27Kip1 existed more in the cytoplasm than in the nucleus in A549 cells, and that p27Kipl was not present in the nucleus, although it was still present in the cytoplasm of HFL-1 cells. Thus, cytoplasmic p27Kip1 may have a role in reducing cell death. EYMIN and co-workers [9, 22] have previously shown that $\mathrm{p} 27 \mathrm{Kip} 1$ induces drug resistance by preventing apoptosis upstream of cytochrome $c$ release in the cytoplasm. As it has

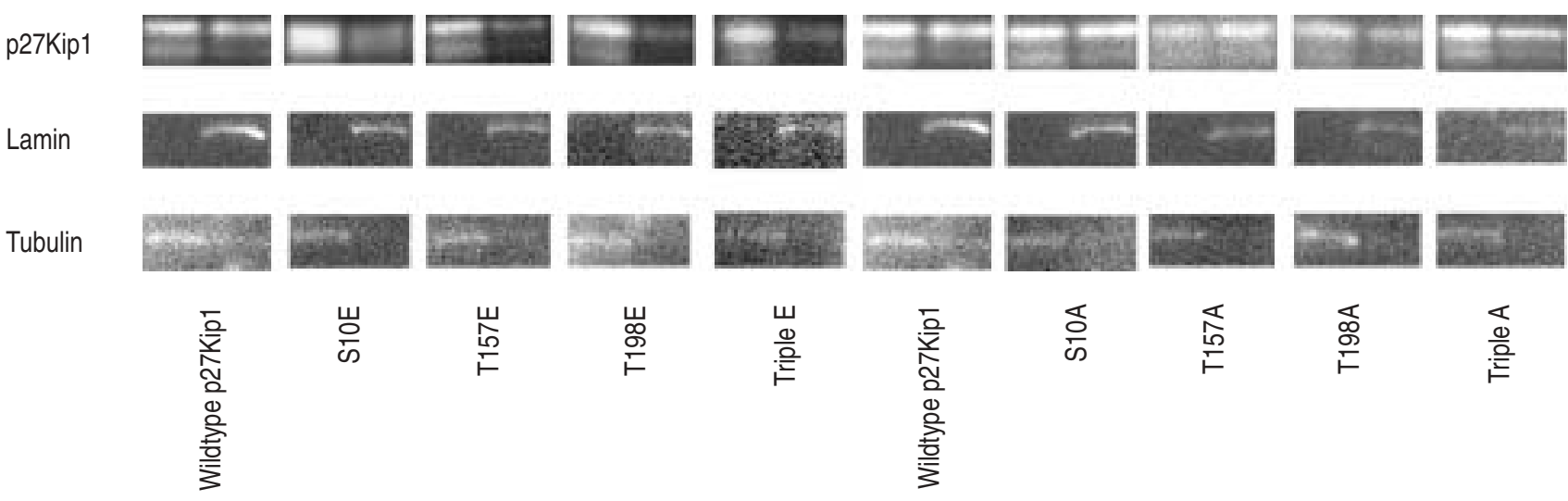

Fig. 6. - Phosphorylation status of p27Kip1 affects subcellular localisation. Substitution with glutamate (E) resulted in the serine (S)10E, threonine (T)157E and T198E proteins localising more in the cytoplasm, as compared to the overexpressed wildtype protein. By contrast, substitution with alanine (A) did not seem to change subcellular localisation of these proteins. 
been reported that cytoplasmic displacement of p27Kip1 is associated with poor prognosis in breast cancer [20] and it has been recognised that $\mathrm{p} 27 \mathrm{Kip} 1$ is localised in the cytoplasm in various circumstances [13-16, 20], cytoplasmic p27 is not considered to be equivalent to loss of function as a CDKI, but to have another role as an anti-apoptotic in malignant cells $[23,24]$. This is comparable to p21Cip1, another CDK Cip/ Kip protein, which also migrates to the cytoplasm [25] and has resistance to apoptosis [26].

In addition, to regulate the p27Kip1 characterisation through sublocalisation, the relationship between the phosphorylation status of S10, T157 and T198 of p27Kip1 and their intracellular localisation was investigated. It was observed that the end product of the phospho-mimetic p27Kip1 mutants at S10, T157 and T198 localised more in the cytoplasm, as compared to the wildtype protein. PARK et al. [27] have suggested that Ad-T187A has the potential to become a novel and powerful gene therapy tool since it had more effect on cell cycle arrest and induction of apoptosis due to its resistance to degradation [4], and also showed that Adp27 suppressed the growth of established lung cancer xenografts. Mutagenesis of the amino acids related to the intracellular localisation could also modify the function of p27Kip1 through its sublocalisation, which might lead to a more promising therapy.

In conclusion, p27Kip1, when expressed physiologically, exists mainly in the cytoplasm, has little effect on cell cycle status and contributes viability in A549 lung adenocarcinoma cells. It was also observed that forced expression of p27Kip1 reduced cell cycle progression and rescued adenovectorinduced apoptosis. In addition, it was surmised that intracellular localisation of p27Kip1 fixes its function, and its localisation was partly determined by its phosphorylation status in this nonsmall cell line cancer cell line.

\section{References}

1. Sherr CJ, Roberts JM. CDK inhibitors: positive and negative regulators of G1-phase progression. Genes Dev 1999; 13: $1501-1512$.

2. Slingerland J, Pagano M. Regulation of the Cdk inhibitor p27 and its deregulation in cancer. J Cell Physiol 2000; 183: $10-17$.

3. Esposito V, Baldi A, De Luca A, et al. Prognostic role of the cyclin-dependent kinase inhibitor p27 in non-small cell lung cancer. Cancer Res 1997; 57: 3381-3385.

4. Park KH, Seol Y, Kim TY, et al. An adenovirus expressing mutant p27 showed more potent antitumor effects than adenovirus-p27 wild type. Cancer Res 2001; 61: 6163-6169.

5. Wang X, Gorospe M, Huang Y, Holbrook N. p27Kip1 overexpression causes apoptotic death of mammalian cells. Oncogene 1997; 15: 2991-2997.

6. Schreiber M, Muller WJ, Singh G, Graham FL. Comparison of the effectiveness of adenovirus vectors expressing cyclin kinase inhibitors p16INK4A, p18INK4C, p19INK4D, p21WAF1/CIP1, and p27KIP1 in inducing cell cycle arrest, apoptosis and inhibition of tumorigenicity. Oncogene 1999; 18: $1663-1676$.

7. Hiromura K, Pippin JW, Fero ML, Roberts JM, Shankland SJ. Modulation of apoptosis by the cyclin-dependent kinase inhibitor p $27^{\mathrm{Kip} 1}$. J Clin Invest 1999; 103: 597-604.

8. Masuda A, Osada H, Yatabe Y, et al. Protective function of p27 (KIP1) against apoptosis in small cell lung cancer cells in unfavorable microenvironments. Am J Pathol 2001; 158: 8796.

9. Eymin B, Haugg M, Droin N, Sordet O, Dimanche-Boitrel MT,
Solary E. p27Kip1 induces drug resistance by preventing apoptosis upstream of cytochrome c release and procaspase3 activation in leukemic cells. Oncogene 1999; 18: 1411-1418.

10. Achenbach TV, Muller R, Slater EP. Synergistic antitumor effect of chemotherapy and antisense-mediated ablation of the cell cycle inhibitor p27KIP-1. Clin Cancer Res 2000; 6: 3006-3014.

11. Sheaff RJ, Groudine M, Gordon M, Roberts JM, Clurman BE. Cyclin E-CDK2 is a regulator of p27Kip1. Genes Dev 1997; 11: 1464-1478.

12. Carrano AC, Eytan E, Hershko A, Pagano M. SKP2 is required for ubiquitin-mediated degradation of the $\mathrm{CDK}$ inhibitor p27. Nature Cell Biol 1999; 1: 193-199.

13. Ishida N, Kitagawa M, Hatakeyama S, Nakayama K. Phosphorylation at serine 10 , a major phosphorylation site of p27Kip1, increases its protein stability. J Biol Chem 2000; 275: 25146-25154.

14. Ishida N, Hara T, Kamura T, Yoshida M, Nakayama K, Nakayama KI. Phosphorylation of p27Kip1 on Serine 10 is required for its binding to CRM1 and nuclear export. $J$ Biol Chem 2002; 277: 14355-14358.

15. Shin I, Yakes M, Rojo F, et al. PKB/Akt mediates cell-cycle progression by phosphorylation of p27Kip1 at threonine 157 and modulation of its cellular localization. Nature Med 2002; 8: $1145-1152$

16. Fujita N, Sato S, Katayama K, Tsuruo T. Akt-dependent phosphorylation of $\mathrm{p} 27 \mathrm{Kip} 1$ promotes binding to 14-3-3 and cytoplasmic localization. J Biol Chem 2002; 277: 2870628713.

17. Ishii $\mathrm{T}$, Matsuse $\mathrm{T}$, Igarashi $\mathrm{H}$, Masuda $\mathrm{M}$, Teramoto $\mathrm{S}$, Ouchi Y. Tobacco smoke reduces viability in human lung fibroblasts: protective effect of glutathione S-transferase P1. Am J Physiol Lung Cell Mol Physiol 2001; 280: L1189L1195.

18. Teramoto S, Matsuse T, Matsui H, Ohga E, Ishii T, Ouchi Y. Recombinant E1-deleted adenovirus vector induces apoptosis in two lung cancer cell lines. Eur Respir $J$ 1999; 13: $1125-1132$.

19. Naruse I, Hoshino H, Dobashi K, Minato K, Saito R, Mori M. Over-expression of p27Kip1 induces growth arrest and apoptosis mediated by changes of $\mathrm{pRb}$ expression in lung cancer cell lines. Int $J$ Cancer 2000; 88: 377-383.

20. Lian J, Zubovitz J, Petrocelli T, et al. PKB/Akt phosphorylates p27, impairs nuclear import of p27 and opposes p27mediated G1 arrest. Nature Med 2002; 8: 1153-1160.

21. Oh S, Kim TK, Hwang DS, Yim J. Involvement of retinoblastoma protein in p27Kip1-induced apoptosis. Cancer Letts 2000; 148: 105-110.

22. Eymin B, Sordet O, Droin N, et al. Caspase-induced proteolysis of the cyclin-dependent kinase inhibitor p27Kip1 mediates its anti-apoptotic activity. Oncogene 1999; 18: 4839-4847.

23. Blagosklonny MV. Are p27 and p21 cytoplasmic oncoproteins? Cell Cycle 2002; 1: 391-393.

24. Coqueret $\mathrm{O}$. New roles for p21 and p27 cell-cycle inhibitors: a function for each cell compartment? Trends Cell Biol 2003; 13: $65-70$.

25. Zhou BP, Liao Y, Xia W, Spohn B, Lee MH, Hung MC. Cytoplasmic localization of p21Cip1/WAD1 by Akt-induced phosphorylation in HER-2/neu-overexpressing cells. Nature Cell Biol 2001; 3: 245-252.

26. Javelaud D, Besancon F. Inactivation of p21WAF1 sensitizes cells to apoptosis via an increase of both p14ARF and p53 levels and an alteration of the Bax/Bcl-2 ratio. $J$ Biol Chem 2002; 277: 37949-37954.

27. Park KH, Seol JY, Yoo CG, et al. Adenovirus expressing p27Kip1 induces growth arrest of lung cancer cell lines and suppresses the growth of established lung cancer xenografts. Lung Cancer 2001; 31: 149-155. 